\title{
Analysis of Hypertension Status and Its Influencing Factors in Some Areas of Hubei Province, China
}

\author{
Lidan Bian ${ }^{*}$, Huanlan Wang2*, Xun Gong33 , Xuanxuan Wang4,5\#, Guo Lu' ${ }^{6 \#, ~ G u o h o n g ~ W a n g 7 \# ~}$ \\ ${ }^{1}$ Outpatient of Dongxihu District of Union Hospital of Huazhong University of Science and Technology, Wuhan, China \\ ${ }^{2}$ Wuhan Hospital of Traditional Chinese and Western Medicine of Tongji Medical College of Huazhong University of Science and \\ Technology, Wuhan, China \\ ${ }^{3}$ Tongji Medical College of Huazhong University of Science and Technology School of Medicine and Health Management, \\ Wuhan, China \\ ${ }^{4}$ Hubei Cancer Hospital, Wuhan, China \\ ${ }^{5}$ Hubei University of Traditional Chinese Medicine, Wuhan, China \\ ${ }^{6}$ Hainan Medical University, Haikou, China \\ ${ }^{7}$ Union Hospital Affiliated to Tongji Medical College of Huazhong University of Science and Technology, Wuhan, China \\ Email:32289275@qq.com, 48656634@qq.com, ${ }^{*}$ caidi87@163.com, " guohongwang2003@163.com, \\ gongxun83@aliyun.com,"78318148@qq.com
}

How to cite this paper: Bian, L.D., Wang, H.L., Gong, X., Wang, X.X., Lu, G. and Wang, G.H. (2020) Analysis of Hypertension Status and Its Influencing Factors in Some Areas of Hubei Province, China. Advances in Aging Research, 9, 14-22.

https://doi.org/10.4236/aar.2020.91002

Received: December 21, 2019

Accepted: January 18, 2020

Published: January 21, 2020

Copyright $\odot 2020$ by author(s) and Scientific Research Publishing Inc. This work is licensed under the Creative Commons Attribution International License (CC BY 4.0).

http://creativecommons.org/licenses/by/4.0/

\begin{abstract}
Objective: To know about the current situation of hypertension in some areas of Hubei Province and analyze the influencing factors. Methods: According to the principle of Stratified sampling, we conducted health examination and questionnaire survey for 1500 residents over the age of 18 at observation point of chronic noninfectious diseases at 10 sub-districts (towns) of Wuhan City, Jingzhou City, Huanggang City, Shiyan City, which used descriptive statistics and logistics to regressively analyze Current situation of hypertension and its influencing factors of residents. Results: Prevalence of hypertension of rural and urban residents over 18 is $27.44 \%$ in Hubei province. There are many differences among prevalence of hypertension of male and female, distribution of BMI of rural and urban residents and prevalence of hypertension and so on, and it has statistical significance ( $P$-value $<0.05$ averagely); logistic regressive analysis result shows that different age, gender, education level, dieting habits (high salt and high oil), family per capita monthly income, BMI have statistical significance on the prevalence of hypertension in urban and rural residents of Hubei Province. Conclusions: The prevalence of hypertension in the residents of five cities and prefectures in Hubei Province is on the trend of rising in ladder form and at a much earlier age. The health education, monitoring
\end{abstract}

${ }^{*}$ Co-first author.

\#Corresponding author. 
and intervention of chronic diseases need to be widely carried out, with emphasis on the intervention of the residents' eating habits of high salt and oil, smoking, drinking and other bad lifestyle.

\section{Keywords}

Hypertension, Affecting Actors, Risk Factors, Effectiveness of Intervention

\section{Introduction}

Located in the middle of China, middle reaches of the Yangtze River, Hubei is a typical region of subtropical monsoon area. It spans $108^{\circ} 21^{\prime} 42^{\prime \prime} \mathrm{E}-116^{\circ} 07^{\prime} 50^{\prime \prime} \mathrm{E}$ and $29^{\circ} 01^{\prime} 53^{\prime \prime} \mathrm{N}-33^{\circ} 6^{\prime} 47^{\prime \prime} \mathrm{N}$. The terrain is generally surrounded by mountains in the East, West and North, and the middle is low and flat, which is an incomplete basin slightly open to the south. Hubei Province covers an area of 185,900 square kilometers, including $56 \%$ mountains, $24 \%$ hills and $20 \%$ plain lakes. Except for the regions of high mountains, most of them are the humid subtropical monsoon climate. The residents in Hubei Province take rice as staple food in their daily diet. They like fish, wine and tea. Including salted and smoked and spicy food. Their living habits are easily affected by the climate and environment. In the past 3 decades, with the rapid development of social economy, the lifestyle of residents has changed a lot. According to the statistical data of Medical Institution Services of Hubei Province, the prevalence of hypertension, hyperglycemia, hyperlipidemia and other chronic diseases is increasing year by year. In order to learn about the current situation of hypertension of residents and analyze its affected factors, researchers conducted a sampling survey of health condition for 1487 residents at 10 sub-districts (towns) of Wuhan City, Jingzhou City, Huanggang City, Shiyan City. The report is as follows.

\section{Data Sources and Method}

\subsection{Data Sources}

According to the distribution of populations, the level of social economic development, regional transport and distribution of medical resources, etc. The method of stratified cluster sampling was adopted. We chose 1487 residents over 18 at observation point of chronic noninfectious diseases at 10 sub-districts (towns) of Wuhan City, Jingzhou City, Huanggang City, Shiyan City as the subjects of research.

\subsection{Method}

\subsubsection{Survey Instrument}

The project form of this health examination was formulated by School of Medicine and Health Management of Tongji Medical College of Huazhong University of Science and Technology, which combines standard test of medical institution services of Hubei Province and the demand for research. It mainly includes de- 
sign process, structure, scale design, sampling framework, sampling methods, and sample size, which collected the age, gender, height, weight, BMI (body mass index), blood routine examination, urine routine examination, electrocardiogram, abdominal B-ultrasound and other information, which were used to preliminarily diagnose their prevalence situations [1]. The questionnaire mainly adopts self-made ones to collect patients' household registration (because of dual economy structure of the urban and rural areas and management system, there are some differences which are now reducing in the level of health insurance between urban and rural residents) educational attainment, career (before retirement), marital status, monthly income per capita, habit of diet, (salted and smoked, hot and sour, high salt and high fat food lover or not), smoker $(\mathrm{Y} / \mathrm{N})$, Alcoholics $(\mathrm{Y} / \mathrm{N})$, drug abuser (standardized medication under advice or not), medical expenses, basic medical insurance and other situations. The disease diagnosis and classification criteria of subject of research are mainly based on Diagnosis of clinical diseases and evaluation criteria of curative effect [2] and guidelines for prevention and control of hypertension in China (2018 version) [3], which is compiled by Ming Sun and Weiwen Wang. Diagnostic criteria of hypertension. In the absence of antihypertensive drugs, the systolic blood pressure $\geq 140 \mathrm{mmHg}$ and/or diastolic blood pressure $\geq 90 \mathrm{mmHg}$ were measured three times. BMI standard, light weight (BMI < 18.5), healthy weight $(18.5 \leq \mathrm{BMI}<24)$, overweight $(24 \leq \mathrm{BMI}<$ $28)$, obesity $(28 \leq \mathrm{BMI})$.

\subsubsection{Method of Gauge Collection}

The survey was conducted by the research workers who had been trained professionally and had more than 3 years of relevant medical knowledge background. The questionnaire was verified one-to-one and the quality of filling in the questionnaire was strictly controlled. In this survey, 1500 questionnaires were sent out and 1487 valid questionnaires were collected, with a recovery rate of $99.13 \%$.

\subsubsection{Statistical Method}

After all the data of physical examination and questionnaire were collected, all the options were Coded quantization. We used Stata 13.0 to conduct input and descriptive analysis, the measurement data were analyzed by t-test and the count data were analyzed by variance, and multi-factors by logistic regression, with statistical significance when $P<0.05$ differently on both sides.

\section{Results and Analysis}

\subsection{General Information}

The basic information of all respondents is shown in Table 1. The results of BMI measurement showed that 322 people (21.65\%) with $24 \leq \mathrm{BMI}<27$; 143 people (9.62\%), $27 \leq \mathrm{BMI}<30$; 91 people $(6.12 \%), 30 \leq \mathrm{BMI}<35$; 23 people $(1.55 \%)$, $\mathrm{BMI} \geq 35$; 322 people were overweight, accounting for $21.47 \%$ which were slightly lower than the results of the national norm [4] [5]; the proportion of obesity was as high as $17.28 \%$, slightly lower than results of domestic and foreign 
Table 1. Basic information and composition of respondents.

\begin{tabular}{|c|c|c|c|}
\hline & Project & Cases & Proportion \\
\hline \multirow[t]{2}{*}{ Gender } & male & 743 & $49.53 \%$ \\
\hline & female & 757 & $50.47 \%$ \\
\hline \multirow{2}{*}{$\begin{array}{l}\text { Household } \\
\text { registration }\end{array}$} & urban & 691 & $46.07 \%$ \\
\hline & rural & 809 & $53.93 \%$ \\
\hline \multirow[t]{5}{*}{ Age (Year) } & $18-29$ & 278 & $18.53 \%$ \\
\hline & $30-39$ & 316 & $21.07 \%$ \\
\hline & $40-49$ & 324 & $21.60 \%$ \\
\hline & $50-59$ & 374 & $24.93 \%$ \\
\hline & $\geq 60$ & 208 & $13.87 \%$ \\
\hline \multirow[t]{4}{*}{ Education level } & Primary school education and below & 171 & $11.40 \%$ \\
\hline & Junior middle school & 413 & $27.53 \%$ \\
\hline & $\begin{array}{l}\text { Senior middle school or secondary vocational } \\
\text { education }\end{array}$ & 465 & $31.00 \%$ \\
\hline & higher education and above & 451 & $30.07 \%$ \\
\hline \multirow[t]{4}{*}{ Career } & Agricultural (fishing)production & 539 & $35.93 \%$ \\
\hline & Industrial production & 316 & $21.07 \%$ \\
\hline & Commercial service industry & 578 & $38.53 \%$ \\
\hline & Public servant & 67 & $4.47 \%$ \\
\hline \multirow[t]{4}{*}{ Marital status } & unmarried & 314 & $20.93 \%$ \\
\hline & married & 819 & $54.60 \%$ \\
\hline & divorced & 289 & $19.27 \%$ \\
\hline & Widowed spouse & 78 & $5.20 \%$ \\
\hline \multirow[t]{3}{*}{ Insurance situation } & Medical insurance of urban workers & 522 & $34.80 \%$ \\
\hline & Medical insurance of urban and rural residents & 973 & $64.87 \%$ \\
\hline & without medical insurance & 5 & $0.33 \%$ \\
\hline \multirow{4}{*}{$\begin{array}{l}\text { Monthly income } \\
\text { per capita }\end{array}$} & Up to 2000 yuan & 337 & $22.47 \%$ \\
\hline & $2001-4000$ yuan & 794 & $52.93 \%$ \\
\hline & $4001-6000$ yuan & 236 & $15.73 \%$ \\
\hline & 6001 yuan and above & 133 & $8.87 \%$ \\
\hline \multirow[t]{3}{*}{ Smoking } & Never & 477 & $31.80 \%$ \\
\hline & smoking & 883 & $58.87 \%$ \\
\hline & smoked & 140 & $9.33 \%$ \\
\hline \multirow[t]{3}{*}{ Drinking } & Never & 399 & $26.60 \%$ \\
\hline & drinking & 823 & $54.87 \%$ \\
\hline & drank & 278 & $18.53 \%$ \\
\hline
\end{tabular}




\begin{tabular}{clcc} 
Continued & & & \\
\hline BMI & Underweight & 191 & $12.73 \%$ \\
& Normal weight & 730 & $48.67 \%$ \\
& overweight & 322 & $21.47 \%$ \\
& Mild obesity & 143 & $9.53 \%$ \\
& Moderate obesity & 91 & $6.07 \%$ \\
& Severe obesity & 23 & $1.53 \%$ \\
& High-salt & 1231 & $82.07 \%$ \\
& not high-salt & 269 & $17.93 \%$ \\
& high fat & 1314 & $87.60 \%$ \\
& not high fat & 186 & $12.40 \%$ \\
\hline
\end{tabular}

research by scholars [6] [7] [8]. The proportion of high salt diet (more than $10 \mathrm{~g}$ salt per day) is as high as $82.07 \%$, and the proportion of high fat diet (more than $30 \%$ of total energy intake per day) is $87.60 \%$.

\subsection{Physical Indicators and Health Condition of Respondents}

The data of the main body constitution indexes of the investigated objects presented abnormal distribution. The mean systolic blood pressure of the subjects was $129.40 \pm 28.50 \mathrm{mmHg}$, mean diastolic pressure was $83.60 \pm 15.30 \mathrm{mmHg}$, among it, mean systolic pressure of urban residents was $133.60 \pm 27.30 \mathrm{mmHg}$, mean diastolic pressure was $86.70 \pm 17.20 \mathrm{mmHg}$, mean systolic blood pressure of rural residents is $126.80 \pm 23.60 \mathrm{mmHg}$, mean diastolic pressure is $81.20 \pm$ $13.40 \mathrm{mmHg}$. BMI: the number of those who were underweight was 191 (12.73\%), 730 people were of normal weight (48.67\%), 322 people were overweight $(21.47 \%), 143$ people were mildly obese $(9.53 \%), 91$ people are moderately obese (6.07\%), There were 23 people (1.53\%) with severe obesity, of which 335 were overweight and obese in urban residents (57.86\%) and 244 were overweight and obese in rural residents (42.14\%). The BMI distribution of urban and rural residents was greatly different, and had statistical significance $\left(\chi^{2}=\right.$ 3.257, $P<0.05)$. The preliminary diagnosis results showed that there were 408 patients with hypertension, the incidence rate was $27.44 \%$; among them, 277 were male patients with hypertension $(67.89 \%), 131$ were female patients with hypertension (32.11\%), the incidence rate of male patients with hypertension was significantly higher than that of female, and the difference had statistical significance with $\chi^{2}=9.531, P<0.01 .283$ urban residents had hypertension (69.36\%) and 125 had hypertension (30.64\%). There was a significant difference between urban and rural residents in the incidence rate of hypertension and it had statistical significance with $\chi^{2}=13.427, P<0.01$. Among the respondents with hypertension, those were aged 18 - 29 was 41 (14.75\% in the same ages); aged 30 - 39, were 68 (21.52\% in the same ages); aged 40 - 49, were 78 (24.07\% in the same ages); aged 50 - 59, were 106 (28.34\% in the same ages); aged 60 and 
above were 115 (55.29\% in the same ages). The incidence of hypertension in different age groups was significantly different, with statistical significance of $\chi^{2}=$ $12.508, P<0.01$.

\subsection{Univariate Analysis of Hypertension}

Univariate analysis was conducted on different age, gender, occupation, education level, marriage, monthly income per capital, BMI, smoking, drinking, dieting habits and insurance, the results showed that there was no significant difference in occupation, marriage, smoking, drinking, insurance. But other factors had statistical significance.

\subsection{Multivariate Analysis of Hypertension}

As shown in Table 2, the incidence of hypertension was taken as the corresponding variable ( 1 for yes, 0 for no), age, gender, education level, dieting habits (high salt and high oil), monthly income per capital and BMI were taken as the independent variables for Logistic regression analysis.

\section{Discussion and Suggestions}

\subsection{There Was Huge Difference in the Incidence of Hypertension between Urban and Rural Residents}

The results showed that the incidence of hypertension in urban and rural residents above 18 years old in Hubei Province was 27.44\%, which was higher than the national norm in 2010 [9]. Among them, the incidence rate of hypertension in men $(37.28 \%$ of the total number of men surveyed) was significantly higher than that in women $(17.31 \%)$, which might be related to men's long-term exposure to smoking, drinking, smoked food and other bad lifestyle as well as social pressure. The incidence rate of hypertension in urban residents $(40.96 \%$ of the total number of urban residents surveyed) is significantly higher than that in rural residents (15.45\% of the total number of rural residents surveyed), which might be related to the exposure to high salt and fat, sour and spicy eating habits

Table 2. Logistic regression analysis on the factors of hypertension in Hubei Province.

\begin{tabular}{cccccccc}
\hline & B & S.E & Wald & $P$-value & OR & \multicolumn{2}{c}{$95 \%$ C.I. } \\
\hline Constant & -2.672 & 0.203 & 25.104 & 0.006 & 0.004 & & \\
Age & 0.743 & 0.037 & 33.529 & 0.017 & 1.983 & 1.578 & 2.319 \\
Gender & 0.481 & 0.054 & 16.031 & 0.003 & 1.427 & 0.943 & 1.792 \\
Education level & 0.252 & 0.027 & 14.824 & 0.011 & 1.152 & 0.723 & 1.682 \\
$\begin{array}{c}\text { Dieting habits } \\
\text { (high salt and oil) }\end{array}$ & -0.378 & 0.035 & 9.572 & 0.017 & 2.071 & 1.736 & 2.531 \\
$\begin{array}{c}\text { monthly income } \\
\text { per capital }\end{array}$ & 0.173 & 0.054 & 8.237 & 0.024 & 1.526 & 0.853 & 1.861 \\
BMI & 0.362 & 0.073 & 11.054 & 0.012 & 1.104 & 0.784 & 1.416 \\
\hline
\end{tabular}


of urban residents, lacking of exercise including psychological pressure from social competition. The results of Logistic regression analysis showed that different age, gender, education level, dieting habits (high salt and fat), monthly income per capital, BMI had statistical significance on the incidence of hypertension in urban and rural residents of Hubei Province. This was basically consistent with the research results of Zhang Qin [10], Li Shicong [11], Wu Jianqiao [12], You Simiao [13] and others. However, the survey found that smoking and drinking were not the main factors affecting the incidence of hypertension among the surveyed, which was different from the research results of some domestic scholars, probably related to the climate environment and long-term formed dieting habits in Hubei Province [14] [15] [16].

\subsection{The Incidence of Hypertension in Residents Represented Younger Trend}

The survey found that the incidence of hypertension in the 18 - 29 years old people reached $14.75 \%$, and the residents' incidence of hypertension showed a significant trend of ladder rise and being younger. The incidence of hypertension in the 50 - 59 years old residents accounted for nearly 30\%, which indicated that the annual increase in the incidence of hypertension had sounded the alarm. With the changes of age, weight gain, diet adjustment, lifestyle, exercise reduction and many other aspects, additionally the lack of health knowledge and awareness, the incidence of hypertension is yearly increasing [17] [18] [19] [20]. The researchers found that 343 hypertensive patients $(84.07 \%$ of hypertensive patients) said it was difficult for them to control their emotions, quick exposure to excitement and anxiety once in trouble, and being emotional in work and life. Only 574 people (38.27\% of the total respondents) expressed concerns about their health status, blood pressure monitoring and health knowledge; 417 urbaners $(60.35 \%$ of the total respondents) concerned about their health, while only 157 rural residents ( $19.41 \%$ of the total respondents) concerned about their health. This showed the difference between the urban and rural in their access to health knowledge and level of health awareness; also suggested that health education required innovative paths and means, as well as continuous publicity and education.

In conclusion, the prevention and treatment of hypertension must be integrated with the local regional environment, population structure, socioeconomic characteristics and culture, focusing on strengthening the intervention of high salt and fat dieting habits, smoking, drinking and other bad lifestyle, monitoring the change of BMI, practising health education for the elderly and obese people in both urban and rural areas, to reduce people's exposure to the risk factors of hypertension [21] [22].

\section{Acknowledgements}

We would like to thanks MD. Huanlan Wang, Ms. Guo Lu and MD. Guohong 
Wang for having prepared the vehicle used in the study. We are grateful to Dr. Xun Gong for reviewing the manuscript. This research was supported by NSFC (Project No. 71373091), youth program of high-end science and technology innovation think tank of Chinese Association for Science and Technology (DXBZKQN-2017-043) and Key Research Center for Humanities and Social Science in Hubei Province (Hubei University of Medicine) (2019YB007).

\section{Conflicts of Interest}

The authors declare no conflicts of interest regarding the publication of this paper.

\section{References}

[1] National Health and Family Planning Commission of PRC. Notice of the Ministry of Health on Printing and Distributing the Interim Provisions on the Administration of Physical Examination.

http://www.nhfpc.gov.cn/zwgk/wtwj/201304/889eb3566368445a84701d24908b61a6. $\underline{\text { shtml }}$

[2] Wang, W.W. (2010) Diagnosis of Clinical Diseases and Evaluation Criteria of Curative Effect. Scientific and Technical Documentation Press, Beijing.

[3] Chinese Committee of Hypertension Prevention and Control Guidelines Revision (2011) Guidelines for the Prevention and Treatment of Hypertension in China 2010. Chinese Journal of Hypertension, 19, 701-702.

[4] Zhu, Y., Shi, J.Z., Luo, X., et al. (2017) Analysis of the Dose-Response Relationship between BMI and Diabetes Mellitus. Chinese Journal of Health Statistics, 34, 887-890.

[5] Liu, Z.S. (2017) A Study on the Relationship between Body Mass Index and Cognitive Function among 1645 Middle-Aged and Young People. Ningxia Medical Journal, 39, 1218-1219.

[6] Abedian, K. and Shahhosseini, Z. (2015) Barriers to Health Education in Adolescents: Health Care Providers' Perspectives Compared to High School Adolescents. International Journal of Adolescent Medicine and Health, 27, 433-436. https://doi.org/10.1515/ijamh-2014-0061

[7] Shahhosseini, Z. and Abedian, K. (2015) Health Care Providers and Adolescents' Perspectives towards Adolescents' Health Education Needs: A Need Assessment Based on Comparative Approach. International Journal of Adolescent Medicine and Health, 27, 73-77. https://doi.org/10.1515/ijamh-2014-0007

[8] Shi, Y., Wang, D. and Wang, J.Y. (2017) Investigation on the Risk Factors of Hypertension in a Community of Hangzhou. Medicine and Society, 30, 41-43.

[9] Xiao, Y.Z., Chen, Y. and Xu, W. (2010) Analysis on the Distribution Characteristics of Hypertension Prevalence and Mean Blood Pressure in Different Nationalities in Yunnan Province. Prevention and Treatment of Cardio-Cerebral-Vascular Disease, 10, 26-27.

[10] Zhang, Q., Gong, X., Wang, X.X., et al. (2018) Hypertension Status and Influencing Factors in Hainan Province. Public Health and Preventive Medicine, 29, 123-125.

[11] Li, S.C., Wen, J. and Deng, X.L. (2015) Analysis on the Prevalence and Risk Factors of Hypertension in Urban Residents of Guangdong Province. Chinese Journal of Public Health, 31, 431-434. 
[12] Wu, J.Q. and Miao, C. (2014) Prevalence and Risk Factors of Hypertension in Rural Areas of Yuyao City. Modern Preventive Medicine, 41, 2315-2317.

[13] You, S.M., Chi, G.F. and Gu, Y. (2017) A Survey of Hypertension in Urban and Rural Residents. Journal of Jilin Medical College, 38, 24-25.

[14] Liu, L., Zhang, M. and Wu, L.S. (2018) Analysis on the Current Situation of Chronic Disease Management in a District of Luzhou City. Medicine and Society, 31, 4-7.

[15] Ming, H., Fu, Q. and He, Z.F. (2017) Analysis of Treatment Compliance and Influencing Factors of Rural Patients with Hypertension. Medicine and Society, 30, 55-59.

[16] Li, C.F., Yan, Y.Q., Guo, Y., et al. (2019) Analysis of Hypertension Management in the Elderly under Different Pension Models. Public Health and Preventive Medicine, 30, 127-130.

[17] Marie, J.O. and Rakesh, K. (2019) Effectiveness of Quarter Standard-Dose Combination Therapy for Initial Management of Hypertension. The National Medical Journal of India, 32, 26-28.

[18] Saulat, S. (2020) Asian Management of Hypertension: Current Status, Home Blood Pressure, and Specific Concerns in Pakistan. Journal of Clinical Hypertension, 1-3.

[19] Zhang, X., Deng, X.Y. and Li, S.F. (2017) Analysis on the Effect of Remote Health Management of Patients with Hypertension in a Hospital Community in Futian District of Shenzhen. Medicine and Society, 30, 67-68.

[20] Babu, G.R., Murthy, G.V.S., Ana, Y., Patel, P., Deepa, R., Neelon, S.E.B., Kinra, S. and Reddy, K.S. (2018) Association of Obesity with Hypertension and Type 2 Diabetes Mellitus in India: A Meta-Analysis of Observational Studies. World Journal of Diabetes, 9, 40-52. https://doi.org/10.4239/wjd.v9.i1.40

[21] Wang, S.B., Kou, C.G. and Liu, Y.W. (2015) Rural-Urban Differences in the Prevalence of Chronic Disease in Northeast China. Asia-Pacific Journal of Public Health, 27, 394. https://doi.org/10.1177/1010539514551200

[22] Garcia, V.E., Dominique, T., Marika, R. and Lisboa, B.P. (2019) Management of Complications of Portal Hypertension. Canadian Journal of Gastroenterology \& Hepatology, 2019, Article ID: 6919284. https://doi.org/10.1155/2019/6919284 